\title{
Extension of the Lean 5S Methodology to 6S with An Additional Layer to Ensure Occupational Safety and Health Levels
}

\author{
Mariano Jiménez ${ }^{1,2} \mathbb{C}$, Luis Romero ${ }^{2, *}{ }^{-0}$, Jon Fernández ${ }^{2}$, María del Mar Espinosa ${ }^{2}$ and \\ Manuel Domínguez ${ }^{2}$ (D) \\ 1 Department of Mechanical Engineering, Technical School of Engineering-ICAI, \\ Comillas Pontifical University, 25, 28015 Madrid, Spain \\ 2 Design Engineering Area, Industrial Engineering School, National Distance Education University (UNED), \\ 38, 28015 Madrid, Spain \\ * Correspondence: lromero@ind.uned.es
}

Received: 12 June 2019; Accepted: 11 July 2019; Published: 12 July 2019

check for updates

\begin{abstract}
This paper proposes an expansion of the Lean 5S methodology, which includes the concept of Safety-Security as 6S. Implementation was done by a standardized process tested in a pilot area that is part of the Integrated Industrial Manufacturing System Laboratory at the Higher Technical School of Engineering (ICAI). The additional 6S phase (Safety-Security) thoroughly reviews all areas of an industrial plant by analyzing the risks at each workstation, which let employees be fitted out with protection resources depending on each of their personal characteristics and to guarantee the safety of the workstation by strictly complying with occupational safety and health and machinery use standards, which must hold a CE certificate of compliance. The main objective was to increase the scope of 5S methodology to respond to the occupational safety and health needs for machines required in optimizing production processes. It is important to remember that companies must guarantee that their employees use personal protection equipment (PPE) at their work posts or stations that protect them properly from risks to their health and safety and that cannot be prevented or sufficiently limited by using collective means of protection or by adopting work organization measures. The industrial resources employed in the pilot area chosen for $6 \mathrm{~S}$ implementation were a sheet metal deformation and cutting line comprised of a punch press, feeder, and winder, as well as a conventional machine tool with minimum safety specifications and without CE certification. Until now, there had been no plans to implement a 6S tool in this laboratory. However, given that the existing safety risk to operators is high, the implementation has led to obtaining optimal results, which justify the success of the 6S methodology proposal. In short, it lets us advance towards the zero accident target.
\end{abstract}

Keywords: lean manufacturing; 6s; PDCA; safety (security); CE certification

\section{Introduction}

Presently, the overall industrial sector demands a response to competitive requirements. The innovation and continuous improvement of existing methodologies are essential for responding to these needs. The price impact on resource purchase and sale processes, as well as the costs associated with production processes, if leaving out quality requirements and delivery timelines, oblige many companies to seek alternatives by implementing methodologies in their organization systems based on the principles of Lean Manufacturing [1-3].

The word 'lean' in reference to an industrial process means that it is versatile, meaning that the parameters can be modified according to clients' requirements. The concept of 'adjusted production' is outlined, since it aims to reduce the amount of resources employed, unlike mass production [4]. 
The methodologies developed under the philosophy of lean manufacturing seek to maximize competiveness of industrial plants via adjusted production, which manages to reduce costs and improve processes. There are a wide variety of methodologies applied during different stages and areas of the plant that permit the entire system to be optimized [5-7].

These methodologies have proven that it is viable to increase the performance of production processes and obtain competitive advantages to remain on the market. Its integration entails an intense process via which 'system weaknesses are analysed to thus be able to determine the areas where lean could be applied' [8,9].

However, due to being a management methodology with the aim of optimizing an organization's production in all senses, it is a long-term process as some features of the production and organizational system must be analyzed and modified $[10,11]$

There are several waste formats at an industrial plant that may appear during the entire production process. These wastes that are generated are termed muda, mura, and muri. With an initial study of these three restrictions, the majority of industrial activities can be optimized [12]. These three words were employed by Toyota for the first time, using the prefix ' $m u$ ' to reflect an intention to improve a system.

The term mura means unevenness. This generates wastes, as inconsistencies within the processes involve higher inefficiency. Some regularity is required so that everything flows correctly and can be stable [13].

Muri means overburden and refers to abundance at the workstations, which entails an obstacle and leads to excessive and unnecessary work: 'an unreasonable effort by personnel, materials or equipment, causing bottlenecks (the accumulation of tasks at a specific phase of the process), downtimes, etc.' [12]. The way to combat muri is by the proper organization of each area of the plant.

Lastly, the term muda translates as waste. This word refers to the activities that employ the available goods and materials, but which do not provide any added value to the product, and therefore, do not contribute to improving its final quality. Eliminating these types of wastes is the main method used to increase productivity, also improving employees' conditions at their workstations. This is why these types of wastes must be identified, which can be classified in seven different types, present in all stages of processes, which were also defined by Taiichi Ohno (1988) [12]. These wastes have different natures, but are all interrelated and circular, as depicted below in Figure 1.

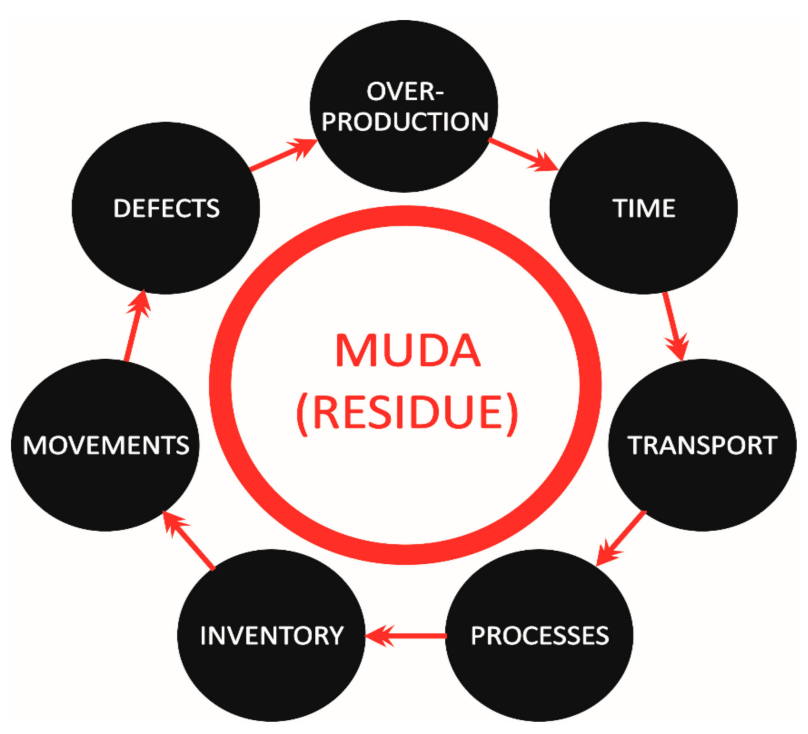

Figure 1. MUDA diagram.

There is an eighth type of waste, which is generated when workers do not use their own imagination to eliminate all these wastes, as they know their workstations better than anyone, and are those who can most contribute to their improvement [14]. 
These failures in the production chains must be identified in order to be able to determine an action plan to remove wastes and thus optimize all industrial activity. The principles of lean manufacturing sprang from this objective.

Lean manufacturing not only affects physical manufacturing processes, but also influences the management of the entire plant and relations between entities. This makes it possible to obtain quick responses within industrial processes, while in parallel eliminating surpluses, expenses, and wasted time [15]. For this reason, we must first know the five basic principles to be able to speak of the lean methodology, which were defined by Womack and Jones (2005) [16]:

$\checkmark$ Establish the quality the client requests to exactly produce what is requested without wastes. Namely, achieving zero defects in industrial processes is the goal to thus achieve this quality and in turn increase productivity.

$\checkmark$ Identify the industrial activities that provide the value required by clients. This lets the tasks be eliminated that do not add value to products, but do entail an extra cost for companies, as well as reducing the quantity of stock needed.

$\checkmark$ Create a continuous flow that progressively adds value to products, so that a continuous improvement system can be applied to processes. This lets the productivity of the industrial activity be increased, along with improving times whenever possible.

$\checkmark$ Employ a PULL system to produce that which clients demand, as this makes it possible to make fast changes to the industrial activities and adapt to their needs.

$\checkmark$ Foster permanent relationships with suppliers via different agreements to guarantee a future with mutual benefits.

While they have been defined in different ways, these principles have the same objectives and origins. The implementation of lean manufacturing methods at an industrial plant must be performed via a disciplined process and, to do so, an order and control method must be used that ensures that the different stages are properly fulfilled. This organized sequencing, linked to increased performance of resources at a plant, assures that the final objective is founded on the principles of quality-cost-delivery time (QCD).

As many people know, $5 \mathrm{~S}$ is a workspace management method that emerged in Japan as a consequence of the application of the kaizen culture (continuous improvement in the personal, family, social, and professional life). The original concept of the $5 \mathrm{~S}$ has socio-historical and philosophical roots [17].

The purpose of this study is to apply the principles of Lean 6S at the Integrated Industrial Manufacturing System Laboratory at the Higher Technical School of Engineering (ICAI). The laboratory has already completely applied the $5 \mathrm{~S}$ tool [18], although the need to develop a phase in the $5 \mathrm{~S}$ methodology for safety has been verified. This new phase can be applied at any working area in an industrial facility, where control of any risk must be guaranteed-first having security of compliance with international safety regulations on the machines used.

In the EU, any product may move freely. The same is true of machines, with the proviso that the machines must comply with minimum safety requirements. The $\mathrm{CE}$ marking indicates that the machine meets these minimum requirements. Therefore, the $\mathrm{CE}$ mark endorses product conformity with regard to the set of obligations the product manufacturer has with regard to the community directives affecting it $[19,20]$. This makes it compulsory to include a sixth S $(6 \mathrm{~S})$ on safety to the $5 \mathrm{~S}$ methodology, as not only will this manage to reduce and even eliminate the different risks that could exist at a workstation, but also assures that the work area complies with current regulations, both on the use of machines and in occupational safety and health. Thus, with this expansion of the methodology to $6 \mathrm{~S}$, the scope is increased and the main objective of the lean $5 \mathrm{~S}$ tool is guaranteed.

The additional phase (safety) centers on thoroughly inspecting and reviewing each process and working area at the industrial plant, to be able to guarantee safety in all areas. Safety is an issue that requires close attention. We must remember that just by applying the regular $5 \mathrm{~S}$ phases, safety is also 
increased due to order and signposting of the workstation, although some activities with associated risks may not be detected. After everything, the application of the rest of the phases entails a large number of modifications at the facility, changes that should also involve eliminating the safety risks of the job and at the facility itself. This is why the existence of a phase $100 \%$ devoted to the analysis of labor risks and protection is considered extremely important.

The regulations used to develop the proposal to expand Lean 6S methodology are:

- Machine Directive (Directive 2006/42/EC) of 17 May 2006, which modifies the previous Directive $95 / 16 / C E$ to 'guarantee in your territory the safety and health of people, particularly the workers and consumers' by-among other means-the CE marking of machines that affect machinery, interchangeable equipment, safety components, lifting accessories, chains, cables and straps, removable mechanical transmission devices and partly-completed machines.

- Regulation (EU) 2016/425 by the European Parliament and Council of 9 March 2016 on personal protective equipment (PPE), which repeals Directive 89/686/EEC by the Council. Both new PPE produced by manufacturers residing in the European Union and new and second-hand PPE imported by a third country are included.

The main objectives of this sixth phase are:

$\checkmark$ Assure the application of safety regulations (occupational risks)

$\checkmark$ Assure the application of safe machine certification

$\checkmark$ Zero accidents

Lean $6 \mathrm{~S}$ also maintains the original objective of eliminating wastes via the control of muda, muri, and mura. Each of the stages of $5 \mathrm{~S}$ remains present in this methodology, just with the addition of a sixth phase. However, the process to apply the methodology is altered by reordering the sequence of application of each of the phases [21].

There are industrial processes that, due to their complexity or need to use special equipment or hazardous substances, entail greater risk and generate the need to evaluate safety in greater depth and perseverance. It is essential to create a safe environment, where employees can work with the maximum normality and convenience possible, with implicit safety. The sixth phase (6S) is considered of vital importance in these cases.

We decided to apply this tool along two different lines, one line for forming items via deformation and cutting of sheet metal, made up of: Punch press, feeder, and winder. These machines have a high risk of incidents. In parallel, the $6 \mathrm{~S}$ methodology has been applied to a resource employed in forming by material removal: Universal cylindrical grinder. This area is complementary to the first, and together, they provide great value to the end results, as it is proven that the protection measures of workers (students) minimize risks, even among the workers (students) with less knowledge of the risks to which one is exposed in a working environment.

\section{Materials and Methods}

As mentioned earlier, the $5 \mathrm{~S}$ tool is applied by a procedure based on preliminary planning, orderly execution, control of results, and later improvements. Therefore, the $5 \mathrm{~S}+$ Safety tool also requires discipline and preciseness to apply the procedure. $6 \mathrm{~S}$ requires the design of a new application process.

After stressing the need to include safety in the methodology, its position must be discussed. Thus, we decided to reorganize the phases in the $6 \mathrm{~S}$ methodology, where safety should be in fourth place for these three reasons:

$\checkmark \quad$ It would not make sense if it took place after audits, as they are performed after the methodology is implemented to verify that the measures established are met.

$\checkmark$ We thought about placing it in fifth position, although since it is about standardizing and pointing out anomalies, it is advisable that safety is established first at workstations and then anomalies 
are detected and normal working conditions are standardized. Further, the last safety phase will be to detect possible risks from anomalies, due to which it could be combined and taken into consideration for the fifth $\mathrm{S}$ (standardize).

$\checkmark$ Finally, it would not make sense for it to hold a higher position, since it is advisable to first eliminate risks by eliminating the unnecessary items that can cause them (1S), the location of necessary items (2S), and cleaning of the workstation (3S).

For the proper implementation of the new phase, the flow chart and PDCA cycle (Plan-Do-CheckAct) has been defined, which should be followed by the implementation team to implement $4 \mathrm{~S}$ (Safety) in a pilot area.

\subsection{Flow Chart}

To develop the flow chart that will define the steps to follow in $4 \mathrm{~S}$, the first step will be to define the people who will take part in the process:

$\checkmark \quad$ The client or person who will perform the activity will be the expert who does the $6 \mathrm{~S}$.

$\checkmark$ The supplier or where implementation will be done: Company/university.

$\checkmark$ Participants in the methodology: OSH technician, company/university, machine, and an expert who does $6 \mathrm{~S}$.

$\checkmark$ Initial milestone: Define the machine to study.

$\checkmark \quad$ Final milestone: Signal on the 6S panel.

Subsequently, the tasks to carry out in this phase must be defined:

- Verify CE marking: It is important to make sure the machine has the CE mark, since via this the manufacturer assures that the machine complies with minimum safety requirements. If the machine does not have $\mathrm{CE}$ marking, speak with the OSH technician for possible adjustments to the machine.

- Check instruction manual: Assure that the workstation or resource has an instruction manual. This manual specifies the optimal working conditions and the restrictions, residual risks, and PPE required.

- Verify that the protections indicated are present and work correctly.

- Verify that the PPE indicated are present and work correctly.

- Study possible risks: If the PPE required is not indicated, possible risks will be studied to define them at a later time.

- If there are risks, define PPE and/or extra protections.

- Define their location, scope, etc.: The location of the PPE/protections will be defined, bearing in mind ergonomics, placement near workstation, and signposting to remind users they must wear suitable protection.

- Identify and check anomalies: whether or not possible risks continue to exist due to user anomaly will be studied, such as not using the necessary PPE for example.

- If they exist, signpost to prevent them: If anomalies occur, there will be signs to remind users of possible dangers.

The flow chart developed is shown below (Figure 2): 


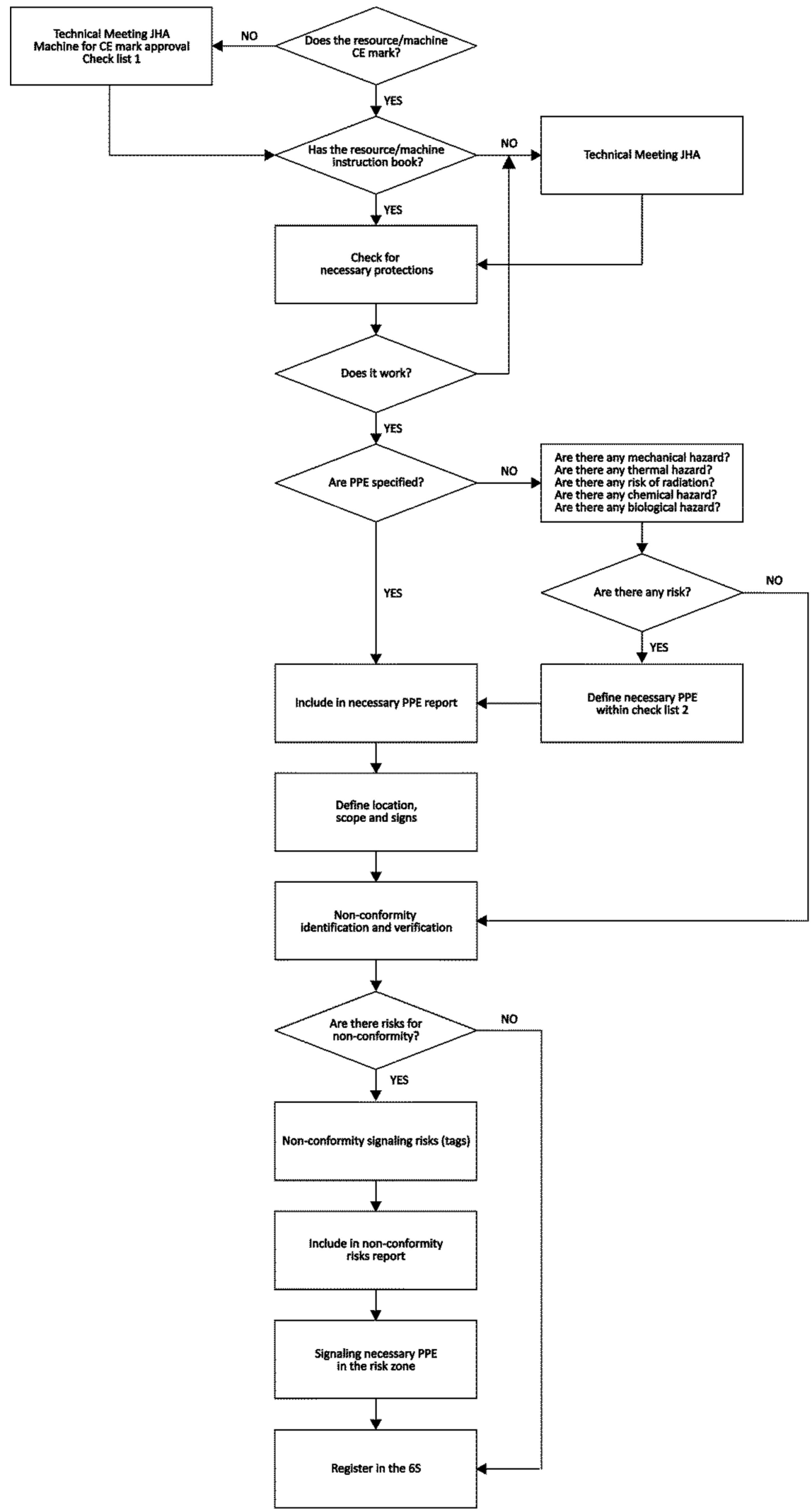

Figure 2. $6 \mathrm{~S}$ flow chart.

Thus, the Lean $6 \mathrm{~S}$ procedure is (the $6 \mathrm{~S}^{\prime}$ are the initials of six Japanese words that represent each of the five stages that make up the methodology): 
1. Remove unnecessary items (Seiri).

2. Order necessary items (Seiton).

3. Eliminate dirtiness (Seiso).

4. Supervise safety (Safety).

5. Signpost anomalies (Seiketsu).

6. Continue improving (Shitsuke).

The phases of $6 \mathrm{~S}$ methodology follow a similar application process to the traditionally employed one. Thus, resources and definitions have been used in our project that was previously used at the laboratory in question. Items have been reused from past implementations in order to uphold thoroughness and accuracy. Nonetheless, all items in the Supervise safety phase were designed starting from zero, as this is a completely new stage at this laboratory.

To apply this tool in the selected pilot area, we created the methodology detailed below.

\subsection{Training of the Implementation Team}

The entire team already had knowledge of the $5 S$ methodology and committed to implementing the new $6 \mathrm{~S}$ methodology in the selected area. This assured that the project is shared with the participation of all members, including directors, who were informed and agree with the entire process.

Further, a small motivation campaign about the project was run prior to starting, so that all members of the laboratory team would be aware of the importance and benefits of the $6 \mathrm{~S}$ methodology. To do so, a series of stickers were distributed in the workshop, and we also held motivating meetings.

\subsection{Selection of Pilot Implementation Area}

The laboratory area selected is where the punch press is located. The characteristics of this implementation area are:

- $\quad$ Size: medium. Clearly delimited area for five person working groups.

- Activity: Teaching how a punch press operates. Production of component samples.

- Stability: Area did not undergo any type of alteration during the four months of implementation.

- Visibility: Located in the central area of the Integrated Industrial Manufacturing System Laboratory, next to a passageway.

- People's attitude: The team is willing and ready to participate.

- Potential: The area selected has large improvement potential.

Below, there are several images of the different areas for the pilot test (Figure 3), before starting the entire implementation process designed:

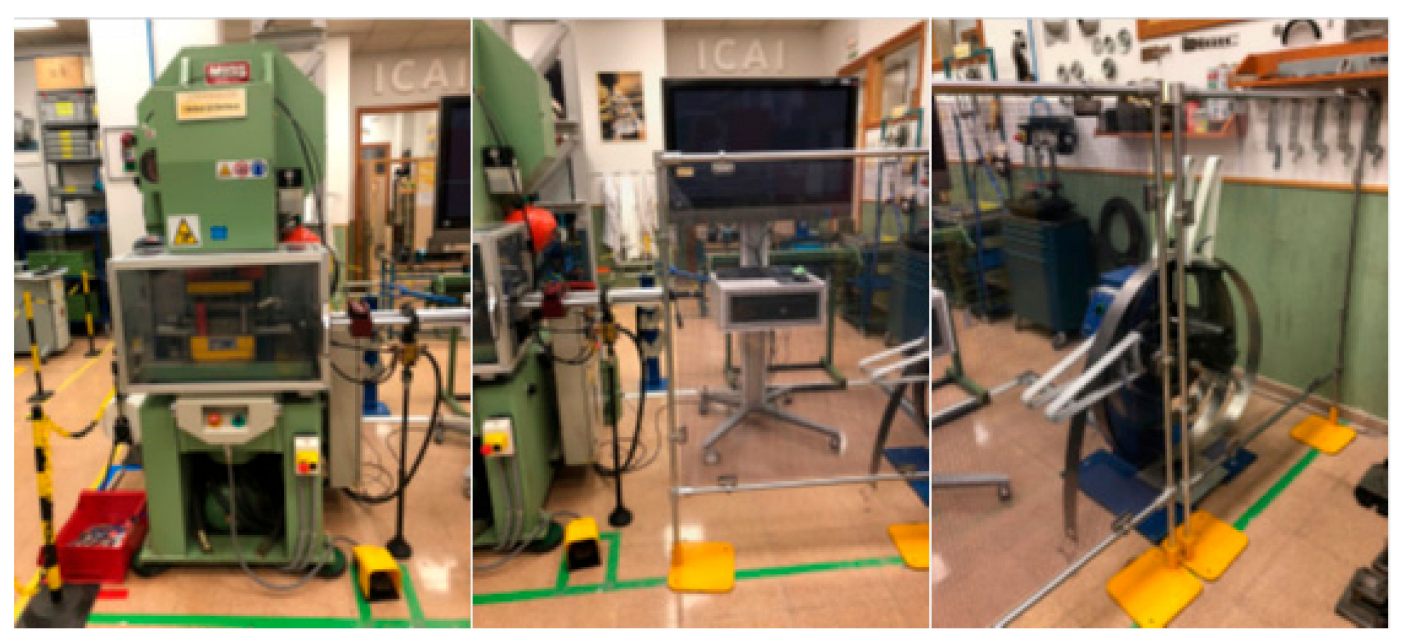

Figure 3. Punch press, feeder and winder areas. 


\subsection{Creation of the 65 Panel}

We created a series of digital $6 \mathrm{~S}$ panels to be able to display the activities done during the implementation process. The $6 \mathrm{~S}$ template that was designed contains photos of the different items in each stage, so the versions before and after application can be compared. Along with these, there are also the pertinent documents designed to accompany each phase.

\section{Results}

As mentioned earlier, each of the $6 \mathrm{~S}$ stages is applied by following the PDCA cycle. This is explained in the independent planning sheets for each of the phases, in which the tasks are divided into which each team member will perform, as well as establishing a date for doing them.

Each of the phases was applied independently, not starting the next until the previous step was completed. The order of application of the six phases followed is that which was established above.

Below, there are data on each phase, along with their accompanying documents and photos, following the proposed scheme for the methodology.

\subsection{Seiri}

Due to being the first phase, there is greater preparation involved. It was necessary to analyze the pilot area established to be able to search for and identify all unnecessary elements, and questionable items, which are detected within the pilot implementation area. These elements are signposted via a series of specific labels for each type. This ensures they are detected at all times. After they are detected, the list of materials, with their locations and comments, was created. After this, we took the decisions necessary to be able to transfer and relocate all excess items. For the questionable items (doubt about their status as necessary or not), we needed to create a cage (temporary storage space) in which to place them after their detection.

Characteristics of the phase:

$\boldsymbol{V}$ Advantages: Elimination of obsolete and duplicate items; good usage of space; reduction of feeling of disorganiatizon.

$\checkmark$ Obstacles: Confusing definitions for that which is necessary and unnecessary; accumulation of items pending classification takes up space; wasting time deciding that is necessary.

$\checkmark$ Indicators: Number of unnecessary items; $\mathrm{m} 2$ of floor freed up; number of items in circulation.

The questionable item identified behind the winder was transferred to the cage created outside of the Integrated Industrial Manufacturing System Laboratory.

The support of the screen, computer, and other ancillary and maintenance items: Boiler, tools, etcetera (items numbers 1 and following on the unnecessary materials list) were relocated in another area of the laboratory, to not block the flow of sheet metal from the winder to the feeder.

\subsection{Seiton}

During this phase, the tasks undertaken were based on identifying and locating the necessary items in the pilot area for the designed function. Namely, the items that are employed either occasionally or daily for the manufacturing processes on the punch press line. To do so, a list of these items was created, with a description of their use and quantity needed for correct operations.

Characteristics of the phase:

$\checkmark$ Advantages: Materials are found easily; reduction of movement of workers and materials; convenience and safety when grabbing materials; reduction of stock; and increased safety.

$\boldsymbol{v}$ Obstacles: Free spaces were then occupied by other objects; assignment of locations were not planned enough.

$\checkmark$ Indicators: Number of items outside of their assigned places; number of unidentified materials, items, and areas. 
Some of the necessary items identified were found in unsuitable sites, which hindered the manufacturing process. For this reason, shelves were created in the pilot area where these items can be stored, both for daily and occasional use, so that they would always be located in the same site (Figure 4).

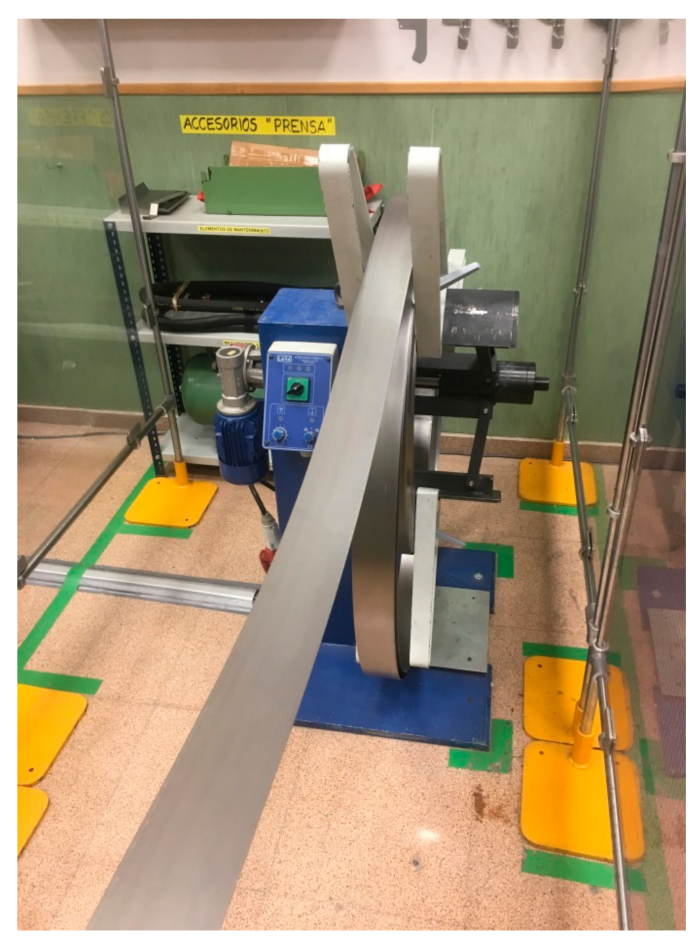

Figure 4. Seiton 1.

The tool board was isolated behind the press and was difficult to access. These daily use tools need to always be accessible, so that the board was moved to one of the protective screens, after making the structure. Access is efficient and fast in this location (Figure 5).

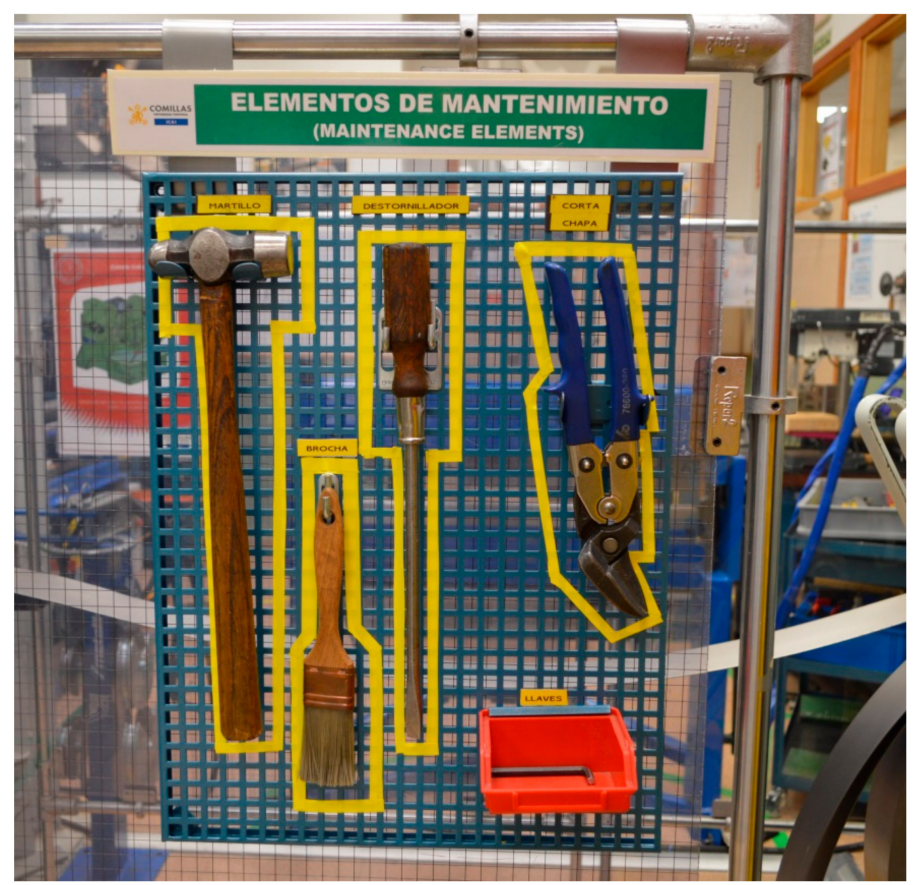

Figure 5. Seiton 2. 


\subsection{Seiso}

During this phase, the main objective was to eliminate all dirtiness in the pilot area, as well as active sources of dirtiness. This assures that the workstation will always be in optimal working conditions. In each case, we looked for solutions to dirtiness problems both immediately and temporarily, which implies that some of them cannot be permanent. Permanent solutions were later proposed to replace the temporary ones to make the phase truly effective.

Characteristics of the phase:

$\checkmark$ Advantages: Improved safety and elimination of health risks, since sources of dirt and grime were eliminated (cutting materials) and complex cleaning activities in difficult to access areas removed; drop in number of interruptions due to needing to clean; waste management optimization; and visibility of anomalies and improved maintenance.

$\checkmark$ Obstacles: Complexity to evaluate the degree of cleanliness present; damage due to people not considering the activity their responsibility; and resignation to sources of dirtiness.

$\checkmark$ Indicators: Number of sources of dirtiness; number of damaged materials; number of difficult locations; and downtime due to failures/breakdowns.

Surplus materials (cutting) entailed a source of dirtiness and risk of cuts, due to being stored at the base of the work table and inside the rails. After cleaning, a series of plastic tubes were installed to prevent the accumulation of dirtiness. In principle, this solution is temporary, given that the tubes were not designed for this purpose. Their effectiveness must be evaluated (Figure 6).

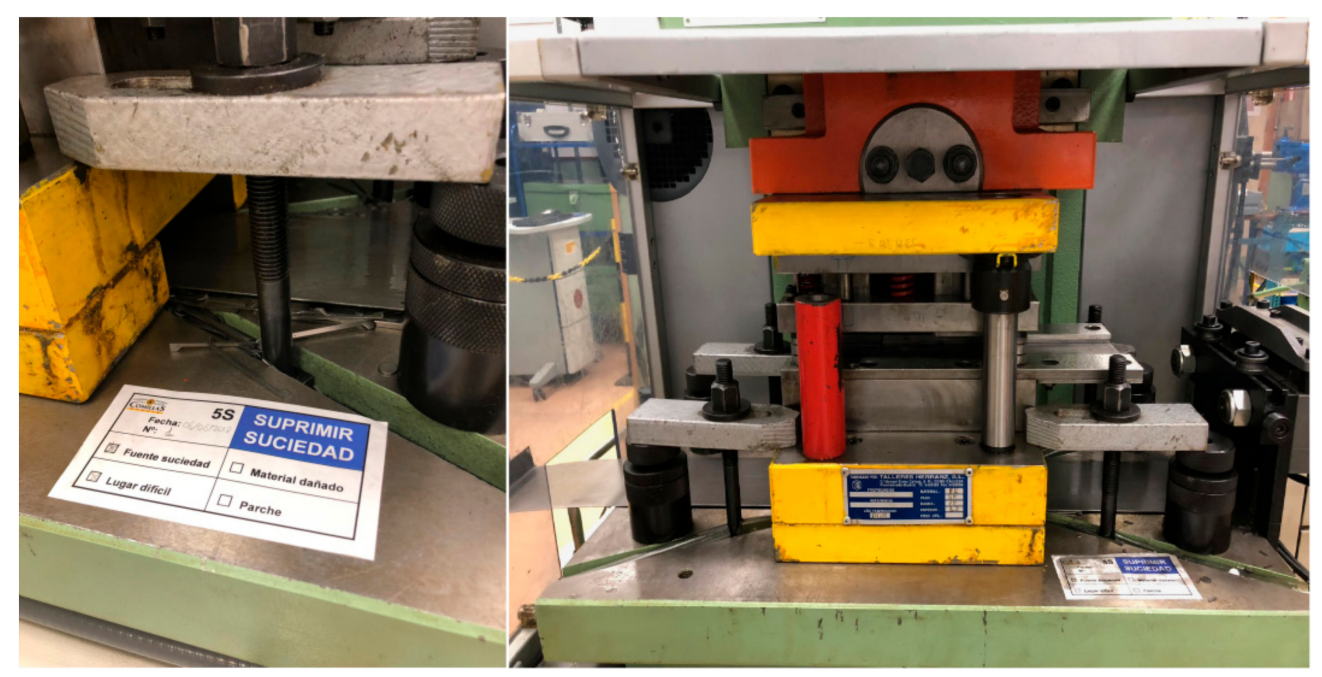

Figure 6. Seiso.

\subsection{Safety}

This is the phase that centers on safety in the pilot area, which thus contributes more value within this implementation process. The objective of this phase is to reduce labor risks to the workers in the working area and ensure that the working area complies with current regulations, both on machines and on occupational safety and health. Therefore, we specifically centered on improving safety. To implement this phase, a flow chart was developed, using it to perform each step until all necessary documents were completed.

Before being able to start implementation, we had to establish the new definitions, tasks, and potential pitfalls that could be connected to a phase such as this one, along with the pertinent parameters.

Along with this, checklists were created that should be used to analyze the safety of the machines and work area, as these checklists verify the level of safety needed according to CE marking and PPE. This was how potential risks were identified. After being identified, solutions could be sought so that 
the workers can thus work in an appropriate and safe environment. This is something that was not carried out in the traditional phases of the $5 \mathrm{~S}$ tool.

A flowchart was created to be able to establish the grounds for the implementation process for the Supervise Safety phase in the applicable area. Following the steps of this flowchart, the safety of the selected items was analyzed, verifying CE marking and the PPEs needed depending on each type. This work was performed at three different points of the plant. The facilitator is in charge of performing the analysis with the chart, while the $\mathrm{OSH}$ technician does the tasks that require technical measures or information linked to the machinery. The plant manager participated when the external sources needed to be contacted.

The flowchart makes reference to two different checklists:

1. The purpose of checklist 1 is to guide the technicians when adapting the machines without $\mathrm{CE}$ marking to the requirements established in current legislation, Directive 2006/42/EC. The checklist has 19 different items on the machines, which ensure minimum compliance with CE marking pursuant to the legislation in Royal Decree 2177/2004 on occupational safety and health. This means that all potential risks and analysis points needed were born in mind. GENERAL ON MACHINERY: Directive 2006/42/EC on general machinery. RD 1644/2008: Rules for the sale and marketing and commissioning of machines.

2. The aim of checklist 2 is to notify technicians about all the PPEs needed that were connected to each workstation. To achieve this, a table was created to establish the relationship between different body parts and the PPEs necessary pursuant to Directive 96/58/EC. Starting on 21 March 2018, Regulation (EU) 2016/425 by the European Parliament and Council of 9 March 2016 on personal protective equipment (PPE), which repeals Directive 89/686/EEC by the Council, entered into force, which is compulsory in all elements and directly applicable in each member state, and therefore, also in Spain. In Spain, the regulation governing PPEs is ROYAL DECREE 773/1997 of 30 May, on the minimum health and safety provisions related to use by workers of personal protective equipment.

The PPEs identified as necessary were placed together on a new metal board over a protective screen, so that they are easy to access by workers at any given time. Each of them has a fixed position that should always be respected. Without these protection elements, you cannot work in this pilot area (Figure 7).

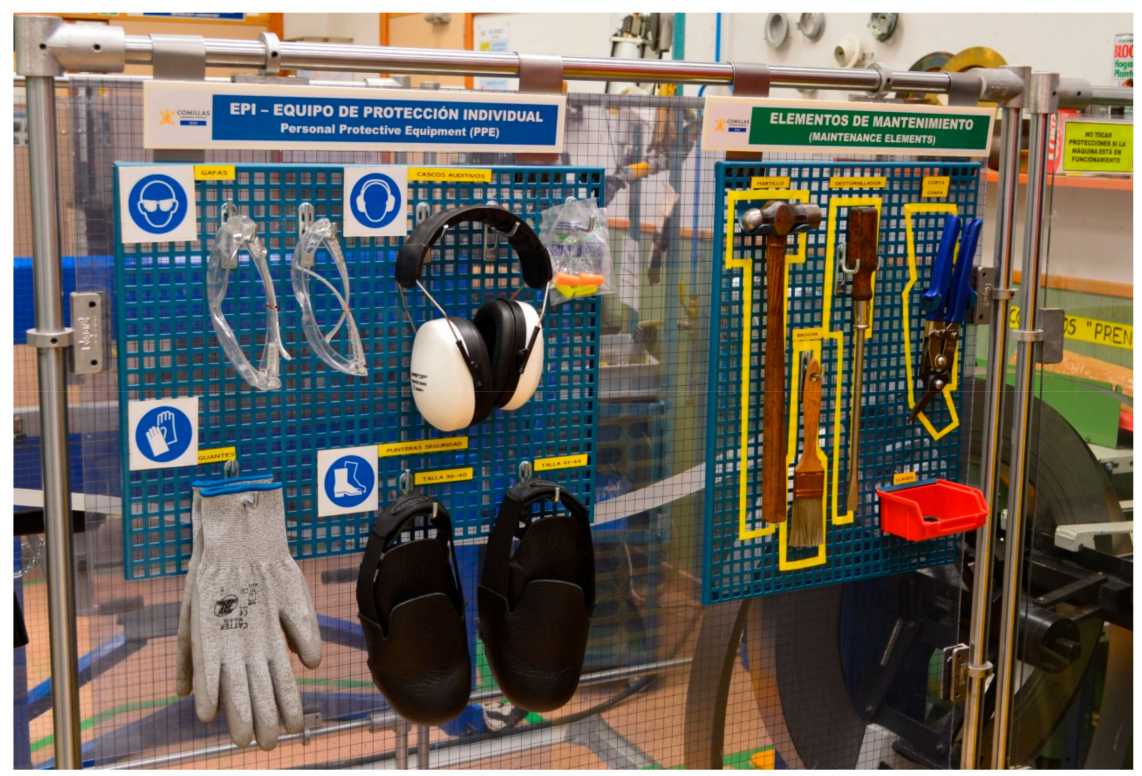

Figure 7. Safety 1. 
The pilot area had two protective screens, but they only covered the press line on one side. This meant that the other side was totally open, entailing a risk for people using the manual folding machine. For this reason, two extra protective screens were installed, so that the entire area is now protected.

The pneumatic feeder did not have the protections needed and thus entailed a safety risk. However, due to being a machine whose operations must be analyzed by students, instead of permanently attaching its frame, we decided to create a screen from transparent material that covers the feeder and lets it be viewed (Figure 8).

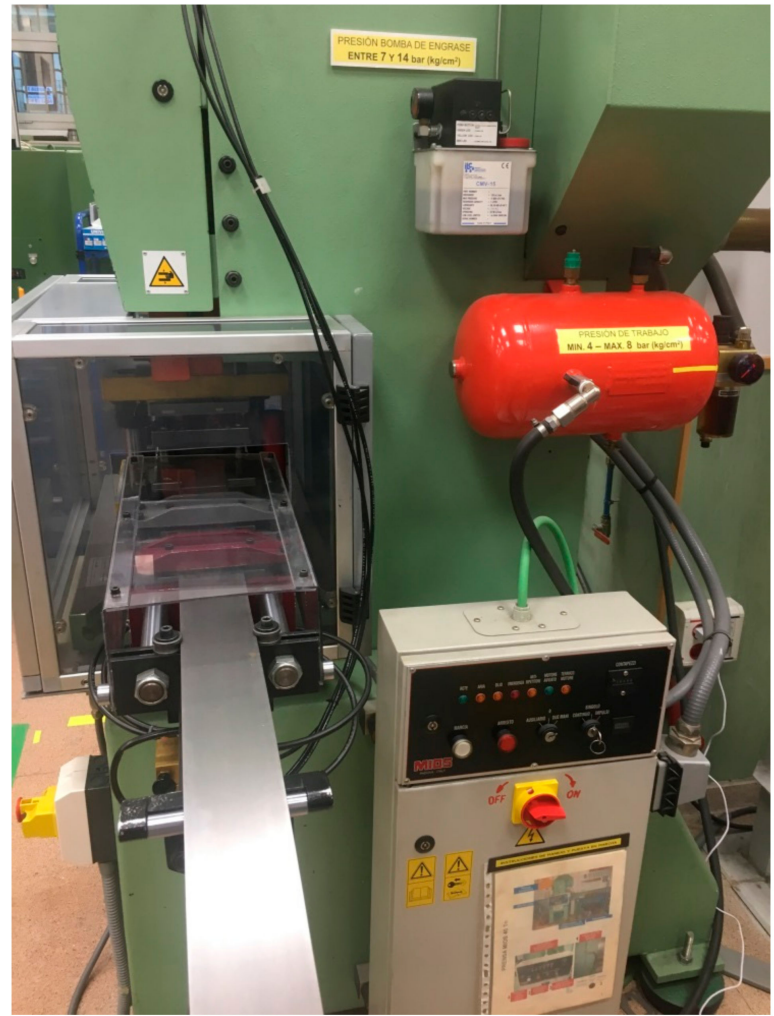

Figure 8. Safety 2.

\subsection{Seiketsu}

The objective of the Signpost Anomalies phase was to eliminate possible situations in which there are values outside of the established limits, so that everything is always in a regular state and in its designated position. By signposting we also sought to simplify all the basic tasks of the press line, so that its use would be as simple as possible and workers would not waste time with small questions. This was carried out by employing a series of different signposting systems (max./min. values, colors, location, etc.).

Traditionally this phase was implemented fourth, after Eliminate Dirtiness, although in this case it was done fifth. This decision was made due to the need of signposting all parameters and items established while doing the previous phases. It does not make sense to conduct this before the Supervise Safety phase, given that new parameters are detected in this phase that need to be measured and items that need to be signposted.

Characteristics of the phase:

$\checkmark$ Advantages: Easy maintenance of order and cleanliness; immediate detection of irregular situations; active knowledge of functions and stock levels; and increased control and safety.

$\checkmark$ Obstacles: Difficult to establish maximum and minimum quantities and technical difficulty in implementing signposting on machines and equipment.

$\checkmark \quad$ Indicators: Ratio between number of points signposted and number of points needed. 
The boiler values were not indicated, so that workers could have had doubts in the event of failure owing to the press pressure. Therefore, this element was signposted with labels that indicate the maximum and minimum values required for proper operation, as well as indicating the needle position necessary via colors (Figure 9).

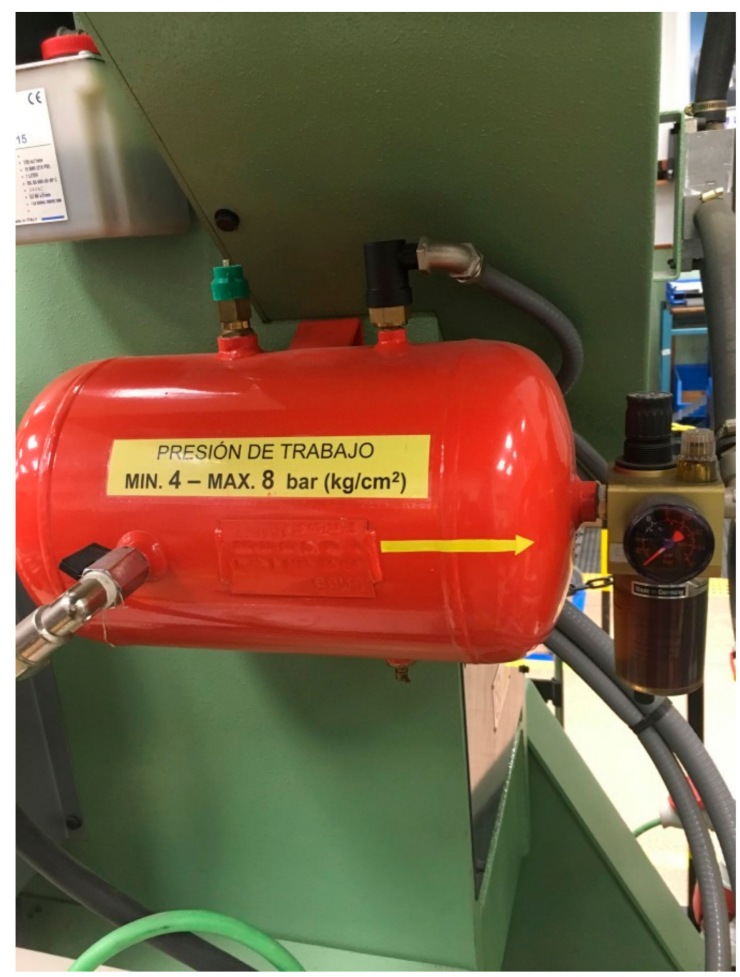

Figure 9. Seiketsu 1.

During the Eliminate Dirtiness phase, signposting was removed from items located on the floor that were in poor condition. Further, a series of items were added inside the pilot area. This made it necessary to signpost again, using green tape (characteristic of this area inside the laboratory) for all these elements, so that their exact position is always known and so that there is nothing out of place (Figure 10).

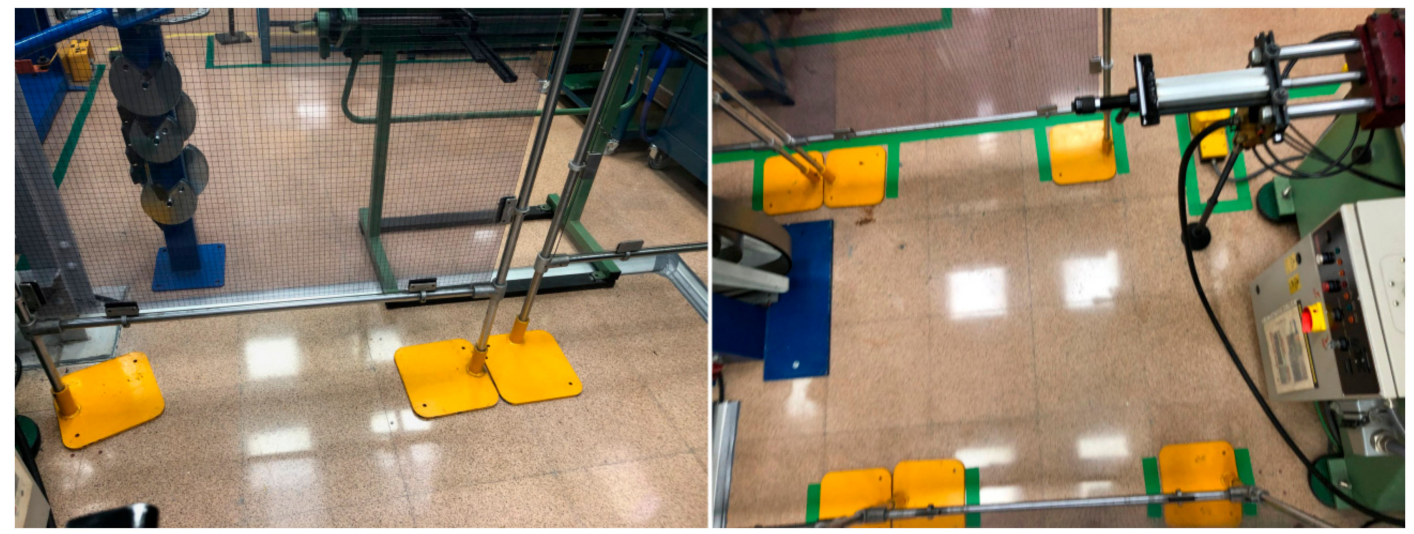

Figure 10. Seiketsu 2.

The boards with diverse items located on the protective screens also required a signposting system. For this reason, yellow tape was used on the tool board, applying it to recreate the exact shape and position of each tool. To signpost safety items, as they have a more complex shape, a photograph was placed to indicate their optimal positions. Everything must always be in its place. 


\subsection{Shitsuke}

The sixth and last phase is primarily based on establishing a methodology with which a periodic analysis is conducted in the pilot implementation area, to ensure that all changes introduced with the $6 \mathrm{~S}$ tool are complied with. This leads to maintaining and even increasing the benefits obtained during the five phases already implemented, while establishing an ambience of routine. If the new processes and changes established are not accepted or respected, the entire implementation will have been in vain. It is not only about auditing the pilot area, but also about finding potential improvement mechanisms to apply.

That is why the planning of this phase is different from the rest. This phase cannot be completed during a fixed period of time, but instead must be performed over an extended period of time to really have an effect. It is not enough to implement the five previous phases, discipline must also be created so that the new modifications become part of the workers' routine and therefore become easier and simpler.

To be able to achieve this, documents were produced that establish a series of controls and audits that evaluate how the pilot area operates. This means that controls can be done to check that the modifications and implementations have really been effective. These audits analyze how processes operate according to the six different phases, or in other words, work as a checklist to monitor the state of all elements in each of the phases. This is not done a single time, but instead must be performed several times over an extended period of time to determine whether the implementation was truly successful (as time passes, part of the improvements established may be lost) and whether the benefits continue.

To be able to audit the implementation of this project, the documents were updated to evaluate the new $6 \mathrm{~S}$ tool designed. This lets us know how effective the process has been, and to find possible improvement mechanisms that should also be implemented. To achieve this, it will be necessary to conduct several analyses over the upcoming months. As mentioned earlier, the processes must be controlled for a specific period of time to know if the new processes have really been interiorized.

Figure 11 shows the pilot area after applying the designed $6 \mathrm{~S}$ methodology. You can see that the modifications done within the entire area of the plant, all with the aim of eliminating any type of waste, improve the productivity of activities, and reduce any risk of accident that could have been present in the area.

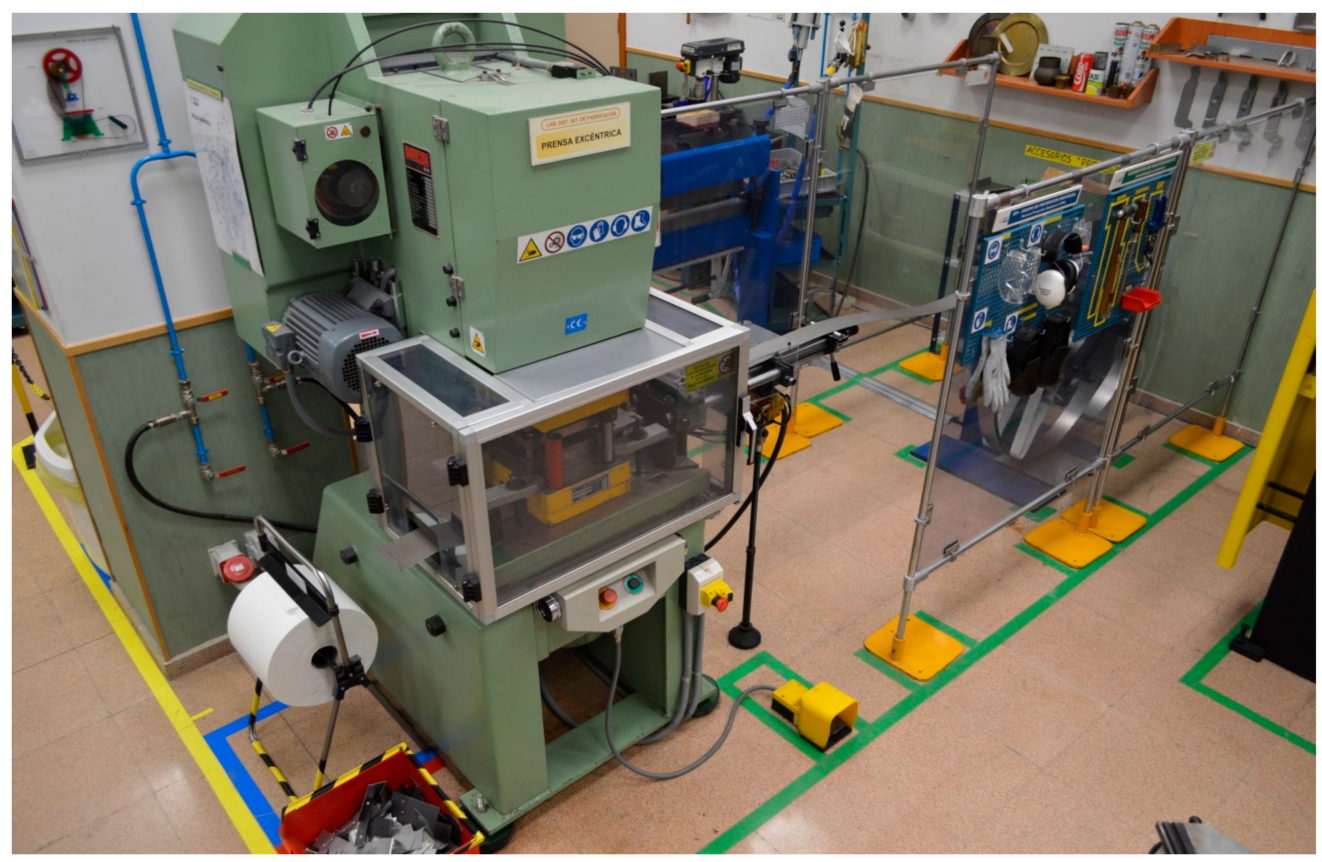

Figure 11. Pilot area with $6 \mathrm{~S}$ methodology. 
The analysis designed was updated and now has a section that evaluates the efficacy of the safety implemented during the new phase 4. With the checklist showed in Appendix A, each of the phases of this tool can be scored, so that we can detect the areas in which the implementation was not so optimal, and thus, seek possible improvements. This checklist should be used on each of the dates established in planning to be able to analyze how the pilot area evolves.

\section{Discussion and Conclusions}

After several months of preparation and implementation, the application process of the $6 \mathrm{~S}$ tool in the selected pilot area was finished, giving rise to a series of obvious modifications at the laboratory, which have the aim of optimizing production and mitigating all possible risks to which operators were exposed, as well as complying with existing regulations. The purpose of the $6 \mathrm{~S}$ tool is to apply all benefits of the traditional lean methodology tool, 5 S, at the selected plant, to manage to improve the quality of the plant's processes and productivity, eliminating all types of wastes, but with an extra focus on safety in the working area. This is why the pilot area selected was the suitable one (due to both the press and universal cylindrical grinder areas being environments with potential risks of accidents).

Via a meticulous study of Lean Manufacturing principles and its multiple tools and concepts, we could compile all information necessary and pertinent in this philosophy $[1,5,9]$. Due to the $6 \mathrm{~S}$ tool being an updated version of the traditional $5 \mathrm{~S}$ tool, before being able to develop a proposal for application, we had to understand the different concepts, benefits, definitions, and pitfalls that could be found within it. There are different versions of the $5 \mathrm{~S}$ tool, although the details they provide are limited and for general application, so that accessing sources of information is difficult.

After understanding the foundations of the $5 S$ tool $[12,17]$, we could make a proposal to apply the new 6S methodology at an industrial laboratory for common manufacturing processes in the industry. By understanding its implementation process (Roll, 2008), it was modified to comply with the requirements of this new version (particularly connected to safety).

There were already previous applications of the $5 S$ tool at the laboratory, which we studied and updated when designing the new methodology [18]. This meant that plant documents and information could be reused, so that application has not led to changes with an excessive impact on the working area. Thus, phase six, Supervise Safety, could be added (implemented fourth in the process) in concordance with the rest, upholding the natural flow of the process. One of the most critical steps in this stage of the project was to keep the team informed and motivated, since it is essential that all members are trained and actively participate in order to ensure that the application of these tools could be successful. In this case, due to being a small team, controlling the involvement of participants was simple, without the need of organizing a large number of tracking meetings (which can occur with larger teams). Recall that implicit demand of compliance with CE marking regulations (Royal Decree 2177/2004) and Directive 96/58/EC.

After the methodology was designed, we could continue with the application of the $6 \mathrm{~S}$ tool in the pilot areas selected. The phases were implemented one by one, respecting the documents and definitions that had been established previously. This let us establish this natural flow for each of the phases in the area. There were no complications for applying phases one to six. Including phase four, centered on safety, which entailed the greatest risk since, unlike the rest, it was an innovative and new concept that had never been applied at this laboratory. One of the largest challenges faced in the practical application of the methodology was to move forward phase by phase, so that the next phase was never started until the previous one had been completed, throughout the implementation chain. At times and after finishing some of the phases and reviewing their pertinent documents, we found new elements linked to them that had not been identified previously. Therefore, controls must be established after finishing the phases to verify that all items taking part in them are identified correctly, and that there are no new ones.

The entire application process was achieved in four months, where the optimal length was between three and six months. The changes and modifications in the pilot area are notable and evident, 
especially in the area of safety features. All items are located in their respective positions and surplus ones were moved (questionable items in the cage), eliminating several wastes that were once in the working area.

Sources of dirtiness were controlled and, using the checklists from the Supervise Safety phase, we could check how all the protections worked and add all those PPEs that were missing for handling items in the area. After this, all signposting missing (or damaged) was implemented, both for old elements and new ones introduced in the preceding phases, thus creating a regular situation in the pilot area in which everything is controlled and labeled.

However, we still cannot draw the conclusion that the application process was a success, as with the Lean Manufacturing tools, there must also be assurance that the methodologies are taken internally in the manufacturing area. In other words, mere application is not enough and valid, but instead now it must be incorporated into the area's activities to ensure that it is accepted there. If not, even if the benefits are significant at first, they could be lost in the future if the $6 \mathrm{~S}$ tool were not to be integrated fully. To ensure that this does not happen, the audits designed in phase 6 were conducted, Continue Improving. They have let us evaluate the effectiveness of the implementation process, and find possible corrective actions that could improve it.

In the first analysis conducted, the audit result was 83/100, which means that-even though the methodology is not perfect-its application worked and was effective. For scores above $75 \%$, let us conclude that the application process worked, although it was not $100 \%$ successful. Such scores are difficult to reach, especially with a new tool that had never been applied before. The evaluation of the Supervise Safety phase must be highlighted that, despite being a new phase, obtained a high score. This is because, due to being new, the majority of the work centered on perfecting this phase. Nonetheless, all phases are equally important, so that all results were analyzed to determine the weakest points. In this case, during the Eliminate Dirtiness phase we detected that the cleaning and corrections done were not fully effective. This is why a corrective action was introduced in order to fix this. The plastic tubes employed to prevent the accumulation of dirt and grime on the rails have not been efficient, due to which a series of aluminum plates matching their exact measurements were ordered as a permanent solution. Another of the problems identified was the organization of the documents produced in each phase, which were not entirely efficient. They have not been sufficiently assessed. They should have been printed and displayed within the pilot area so that the work could be appreciated, and the team members could have provided feedback. This will be borne in mind for future applications of the $6 \mathrm{~S}$ tool.

These results are not enough to evaluate the efficacy of applying the $6 \mathrm{~S}$ tool methodology. These audits should continue to be performed in upcoming months, as set out in planning. Only in this way can the true value of the project be determined. While the contributions made in the pilot area are already significant, if the tool is not respected and accepted, the benefits it has made could be lost, meaning that the application would not have been successful.

In parallel to the implementation of the Lean 6S methodology, the research team has outlined as the next working line to expand the $6 \mathrm{~S}$ methodology to a new ' $7 \mathrm{~S}^{\prime}$ phase that would consolidate prior phases through compliance commitment and coordination with the rest of the department involved in safety and prevention standards.

Author Contributions: Conceptualization: M.J. and J.F.; Methodology: M.J., L.R., J.F., M.d.M.E. and M.D.; Software: J.F. and M.d.M.E.; Validation: M.d.M.E. and M.D.; Formal analysis: L.R. and M.D.; Investigation: M.J., L.R. and J.F.; Resources: L.R., M.d.M.E. and M.D.; Data curation: L.R., M.d.M.E. and M.D.; Writing-original draft preparation: M.J., L.R. and J.F.; Writing-review and editing: M.d.M.E. and M.D.; Visualization: M.J., M.d.M.E. and M.D.; Supervision: M.J. and L.R.; Project administration: M.J., M.d.M.E. and M.D.; Funding acquisition: NA.

Funding: This research received no external funding.

Acknowledgments: Thank you to all the organizations and people who participated in the project, particularly to professors and students who have a genuine will for change and a spirit of continuous improvement. Thanks also to the Industrial Engineering School of UNED for the support that they provided with the project '2019 - ICF06'.

Conflicts of Interest: The authors declare no conflict of interest. 


\section{Appendix A}

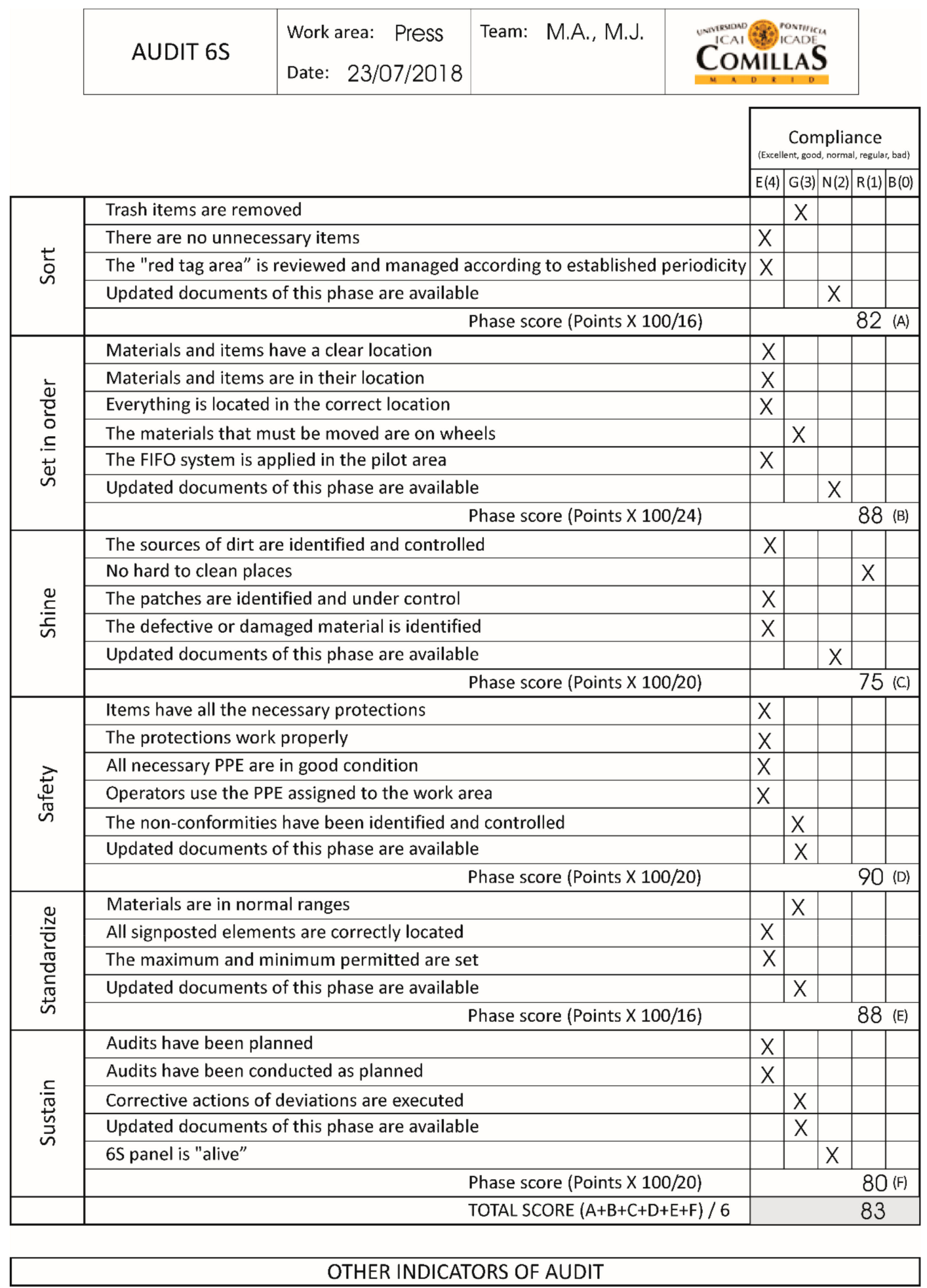

\begin{tabular}{|l|l|}
\hline № new items not necessary & \\
\hline № items out of place & \\
\hline № items without location & \\
\hline
\end{tabular}

\begin{tabular}{|l|l|}
\hline № items without identification & \\
\hline № new sources of dirt & \\
\hline № new patches or damaged material & \\
\hline
\end{tabular}

Figure A1. Audit Analysis. 


\section{References}

1. Bhamu, J.; Singh, K. Lean manufacturing: Literature review and research issues. Int. J. Oper. Prod. Manag. 2014, 34, 876-940. [CrossRef]

2. Gil, M. Cultura LEAN; Profit Editorial: Brescia, Italy; Barcelona, Spain, 2007.

3. Locher, D. Lean Office: Metodologia Lean en Servicios Generales, Comerciales Y Administrativos; Profit Editorial: Brescia, Italy; Barcelona, Spain, 2017.

4. Rajadell, M.; Sánchez, J.L. Lean Manufacturing. La Evidencia de Una Necesidad; Ediciones Díaz de Santos: Madrid, Spain, 2010.

5. Charron, R.; Wiggin, H.; Voehl, F.; Harrington, H.J. The Lean Management Systems Handbook; Productivity Press, Taylor and Francis: London, UK, 2014.

6. Cuatrecasas, L. Ingeniería de Procesos Y de Planta: Ingeniería Lean; Profit Editorial: Brescia, Italy; Barcelona, Spain, 2017.

7. Dailey, K.W.; Wieckhorst, D.; Welch, B. Lean Manufacturing Pocket Handbook; DW Publishing: Orlando, FL, USA, 2003.

8. Castillejos, A. Integración de Design Thinking en herramientas aplicadas a Lean Manufacturing. Proy. Fin De Carrera, Univ. Politécnica De Madrid. 2016. Available online: http://oa.upm.es/44161/ (accessed on 11 July 2019).

9. Zhou, B. Lean principles, practices, and impacts: A study on small and medium-sized enterprises (SMEs). Ann. Oper. Res. 2016, 241, 457-474. [CrossRef]

10. Brau, S.J. Lean Manufacturing 4.0: La Evolución Tecnológica del Lean. Guía Práctica sobre la Correcta Utilización de Tecnología en Proyectos Lean; Comillas Pontifical University: Madrid, Spain, 2016.

11. Cuatrecasas, L. Lean Management: La Gestión Competitiva Por Excelencia; Profit Editorial: Brescia, Italy; Barcelona, Spain, 2015.

12. Ohno, T. Toyota Production System: Beyond Large-Scale Production; Productivity Press: New York, NY, USA, 1988.

13. Robinson, S.; Radnor, Z.J.; Burgess, N.; Worthington, C. SimLean: Utilising simulation in the implementation of lean in healthcare. Eur. J. Oper. Res. 2012, 219, 188-197. [CrossRef]

14. Pedraza, L.M. Mejoramiento productivo aplicando herramientas de manufactura esbelta. Rev. Soluc. De Postgrado 2013, 3, 175-190.

15. Navarro, F.J. Implementación de herramientas Lean Manufacturing en la planta de producción de un Proveedor del Sector Automoción. Master's Thesis, Universitat Politècnica de Catalunya, Barcelona, Spain, 2017.

16. Womack, J.P.; Jones, D.T. Lean Thinking: Cómo Utilizar el Pensamiento Lean Para Eliminar Los Despilfarron y Crear Valor en la Empresa; Grupo Planeta: Madrid, Spain, 2005.

17. Kobayashi, K. What is 5S? A Content Analysis of Japanese Management Approach. Master's Thesis, Griffith University, Southport, QLD, Australia, 2005.

18. Jiménez, M.; Romero, L.; Domínguez, M.; Espinosa, M.M. 5S methodology implementation in the laboratories of an industrial engineering university school. Saf. Sci. 2015, 78, 163-172. [CrossRef]

19. Azofra, I. Adecuación de maquinaria Industrial al Real Decreto 1215/1997 de equipos de trabajo. Proyecto Fin de Máster, Universidad Pública de Navarra, Navarra, Spain, 2013.

20. Tapia, J.; Adarve, J. Prevención de riesgos laborales: Protección de las máquinas. In Anales de Mecánica Y Electricidad Proceedings of the Asociación de Ingenieros del ICAI; Comillas Pontifical University: Madrid, Spain, 2006; pp. 36-40.

21. Roll, D. An Introduction to 6S; Vital Enterprises: Beaverton, OR, USA, 2008.

(C) 2019 by the authors. Licensee MDPI, Basel, Switzerland. This article is an open access article distributed under the terms and conditions of the Creative Commons Attribution (CC BY) license (http://creativecommons.org/licenses/by/4.0/). 